\title{
The Monthly Variation Process of Water Temperature in Jiaozhou Bay
}

\author{
Dongfang Yang ${ }^{1,2, a}$, Haoyuan Ren ${ }^{1}$, Dong Yang ${ }^{1}$, Longlei Zhang ${ }^{1}$, Haixia $\mathrm{Li}^{1}$ \\ ${ }^{1}$ Accountancy Shool, Xijing University, Xian 710123, China; \\ ${ }^{2}$ North China Sea Environmental Monitoring Center, SOA, Qingdao 266033, China;
}

\begin{abstract}
According to the investigation materials in the water field of Jiaozhou Bay from May to October 1980 , this paper studies the water temperature of Jiaozhou Bay and the monthly variation. The results show that in each month from May to October, the water temperature varies from 10.80 to $26.53{ }^{\circ} \mathrm{C}$ in the waters of Jiaozhou Bay, and the interval length of water temperature is $15.73{ }^{\circ} \mathrm{C}$. This paper determines the changing curve of the high or low value of the water temperature at each month and establishes the corresponding simulation equation. The high water temperature reaches a maximum of $26.53{ }^{\circ} \mathrm{C}$ in August, and the low water temperature reaches a maximum of $24.69^{\circ} \mathrm{C}$ in August. In the water bodies of Jiaozhou Bay, the high or low water temperature both reaches its highest value in August. In June, the increasing rate of peak value in water temperature is the fastest, and the increasing rate of low value in water temperature is relatively fast. In October, the decreasing rate of the peak water temperature is relatively fast, and decreasing rate of the lowest value in water temperature is the fastest. From May to August, the high (low) water temperature is on the rise in Jiaozhou Bay. The high water temperature appears in the western waters of the top of bay and the western waters inside of bay mouth. The low water temperature appears in the eastern and southern waters outside of bay mouth. In September and October, the high (low) water temperature in the Jiaozhou Bay water bodies is decreasing. The high water temperature appears in the eastern and southern waters outside of bay mouth, and the low water temperature appears in the western waters of the bayhead.
\end{abstract}

\section{Introduction}

The ocean has played a significant role in climate regulation throughout the Earth [1]. Coastal water temperature and temperature changes affect global climate change [2]. Air and water temperature have a strong effect on plants, animals, microorganisms and human body [3-10]. Therefore, studying the changes in water temperature and the water fields with high water temperature will provide important assistance in protecting the marine environment and maintaining sustainable ecological development. Based on the investigation materials in 1980, this paper analyzes the water temperature, horizontal distribution and the changing of sources in Jiaozhou Bay, and studies the changes, processes and sources of water temperature. These provide a scientific background for comprehensive analysis of water temperature sources and high temperature fields in Jiaozhou Bay, and offer a theoretical basis for changes of water temperature in environmental impacts.

\section{Investigation water fields, materials and methods}

\subsection{Natural environment of Jiaozhou Bay}

Jiaozhou Bay is located in the south of Shandong Peninsula, ranging in $120^{\circ} 04^{\prime}-120^{\circ} 23^{\prime} \mathrm{E}, 35^{\circ} 58^{\prime}-36^{\circ} 18^{\prime} \mathrm{N}$, bounded by Tuan Island and Xuejiao Island, and connecting to the Yellow Sea. With the area of $446 \mathrm{~km}^{2}$ and average depth of $7 \mathrm{~m}$, it is a typical semi-enclosed bay. There are more than 10 rivers flow to the sea, of which the Dagu River, the Yang River, and some rivers in the urban of Qingdao such as Haipo River, Licun River and Loushan River, are the rivers with large runoff and sediment concentration. These rivers are ephemeral streams with obviously seasonal hydrological characteristics[11, 12].

\subsection{Materials and methods}

The investigation materials about the water temperature in the water bodies of Jiaozhou Bay from May to October of 1980 applied in this study are offered by the North China Sea Environmental Monitoring Center of 
State Oceanic Administration. From May to October, setting ten stations to take water samples from the surface and bottom respectively: $\mathrm{H} 34, \mathrm{H} 35, \mathrm{H} 36, \mathrm{H} 37$, H38, H39, H40, H41, H82 (as shown in figure 1). Based on the water depth to take samples:

Taking from surface and bottom layer, where the depth > 10m; $10 \mathrm{~m}$.

Taking from surface layer only, where the depth $<$

This investigation method conforms to the national standards, and is recorded in The Specification for Marine Monitoring (1991) [13].

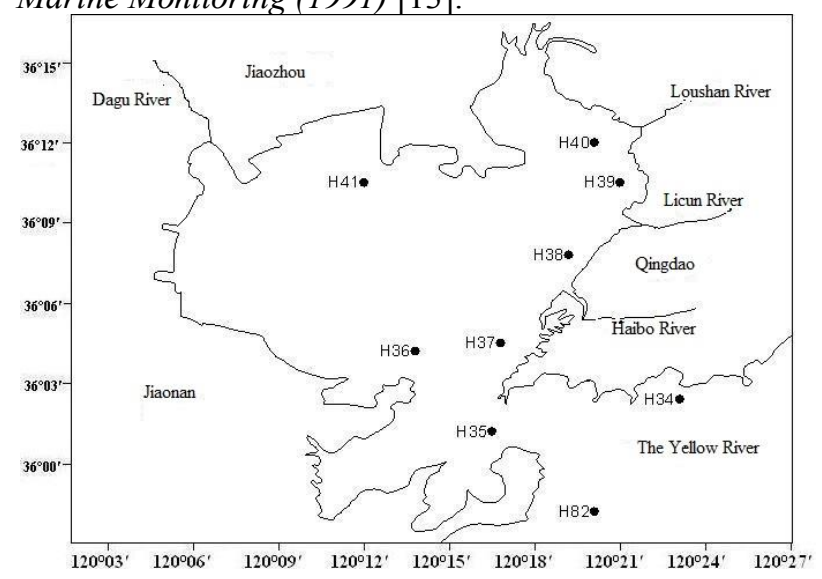

Fig.1 Investigation sites in Jiaozhou Bay

\section{Results}

\subsection{Water temperature degree}

From May to October, the water temperature varies from 10.80 to $26.53{ }^{\circ} \mathrm{C}$ in the water body of Jiaozhou Bay, indicating that the interval length of seawater temperature change is $15.73{ }^{\circ} \mathrm{C}$. In May, the water temperature in the Jiaozhou Bay waters ranges from $10.80^{\circ} \mathrm{C}$ to $16.30{ }^{\circ} \mathrm{C}$, and the water temperature is relatively low. In June the water temperature in the surface water increases significantly, and ranges from $16.17^{\circ} \mathrm{C}$ to $23.73^{\circ} \mathrm{C}$, which is relatively high. In July, the water temperature in the surface water continues to increase. The water temperature in the waters ranges from $19.77^{\circ} \mathrm{C}$ to $26.14^{\circ} \mathrm{C}$, and the water temperature is very high. In August, the water temperature in the surface water body increases slowly, and the water temperature ranges from $24.69^{\circ} \mathrm{C}$ to $26.53{ }^{\circ} \mathrm{C}$, which is in a very high level. In September, the water temperature decreases significantly. The water temperature in the waters of Jiaozhou Bay ranges in $23.11-24.50^{\circ} \mathrm{C}$, which is relatively high. In October, the water temperature in the water body decreased further. The water temperature ranges within $13.98 \sim 20.12{ }^{\circ} \mathrm{C}$, which is relatively low. Therefore, in May, June, July, August, September and October, the water temperature varies from $10.80^{\circ} \mathrm{C}$ to $26.53{ }^{\circ} \mathrm{C}$ in the waters of Jiaozhou Bay, and the water temperature all reaches above $10.00{ }^{\circ} \mathrm{C}$. This indicates that in terms of water temperature changes, from May to October, the water temperature in the whole waters of Jiaozhou Bay is relatively high (Table 1).

Tab.1 The water temperature in the surface waters of Jiaozhou bay in each month

\begin{tabular}{lcccccc}
\hline Period & May & June & July & August & September & October \\
\hline Water temperature $/{ }^{\circ} \mathrm{C}$ & $10.80-16.30$ & $16.17-23.73$ & $19.77-26.14$ & $24.69-26.53$ & $23.11-24.50$ & $13.98-20.12$ \\
\hline
\end{tabular}

\subsection{The changes of maximum water temperature in the surface waters}

In the waters of Jiaozhou Bay, taking the monthly maximum water temperature at all stations as the high monthly water temperature. In May, June, July, August, September and October, the corresponding monthly maximum water temperatures are $16.30^{\circ} \mathrm{C}, 23.73^{\circ} \mathrm{C}$, $26.14^{\circ} \mathrm{C}, 26.53^{\circ} \mathrm{C}, 24.50^{\circ} \mathrm{C}$ and $20.12^{\circ} \mathrm{C}$ (Figure 2). A curve is formed by these high water temperature values, and equation (1) is established for simulation. The simulated curve is highly fitted to the actual curve, $\mathrm{R} 2=$ 0.984 .

$$
y=-1.371 x^{2}+21.19 x-54.93
$$

In the formula, $y$ is the monthly high water temperature, and $x$ represents the month. $(x=5,6,7,8,9$, 10)

In each month, in June, July, August, September and October, the changing rate of monthly water temperature high value are $23.73-16.30=7.43,26.14-23.73=2.41$, $26.53-26.14=0.39, \quad 24.50-26.53=-2.03,20.12-24.50=$ -4.38 .

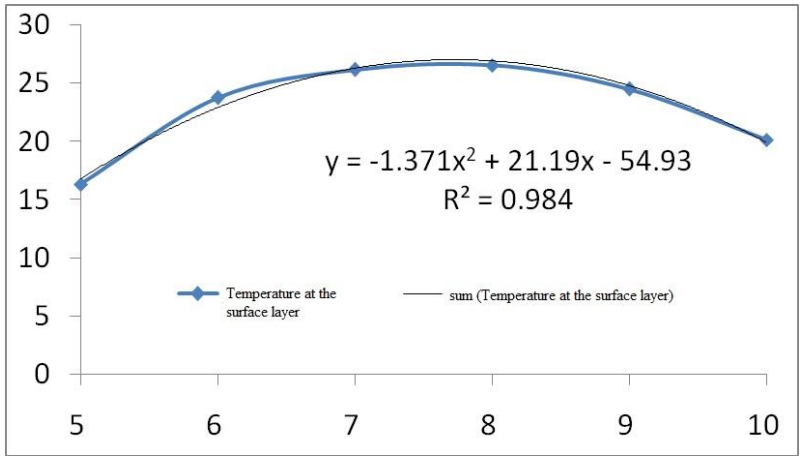

Fig.2 the change of high value of water temperature at the surface in Jiaozhou Bay in 1980

The rate at which the water temperature rises is highest in June, and the rate at which the water temperature drops fastest is in October. The rate at which the water temperature rises in July is basically the same as the rate at which the water temperature in September drops. In August, the rate at which the water temperature rises is very small. Whether the water temperature is high or not, the rate of rising or falling, from high to low, the rate in June $>$ the rate in October $>$ the rate in July $>$ the 
rate in September > the rate in August.

\subsection{The changes of minimum water temperature in the surface waters}

In the waters of Jiaozhou Bay, the lowest monthly water temperature at all stations is the low value of Jiaozhou Bay waters. In May, June, July, August, September and October, the corresponding monthly minimum water temperatures are $10.80^{\circ} \mathrm{C}, 16.17^{\circ} \mathrm{C}, 19.77^{\circ} \mathrm{C}, 24.69^{\circ} \mathrm{C}$, $23.11^{\circ} \mathrm{C}$ and $13.98^{\circ} \mathrm{C}$ (Figure 3). The curve is formed by the lowest water temperature, and the equation (2) is established for simulation. The simulation curve is fitted to the actual curve height, $\mathrm{R} 2=0.987$.

$$
y=-0.484 x^{3}+9.243 x^{2}-53.20 x+106.5
$$

In the formula,y is the monthly high water temperature, and $\mathrm{x}$ is the month value $(\mathrm{x}=5,6,7,8,9,10)$

In June, July, August, September and October, the monthly water temperature low value change rate is $16.17-10.80=5.37,19.77-16.17=3.60,24.69-19.77=4.92$, $23.11-24.69=-1.58,13.98-23.11=-9.13$.

In June, the rate at which the low water temperature rises is the highest, and the lowest in July. The rate at which the low water temperature drops is the highest in October, and the lowest in September. The rate at which the low water temperature is rising or declining, from high to low, the sequence is the rate of October $>$ the rate of June $>$ the rate of August $>$ the rate of July $>$ the rate of September.

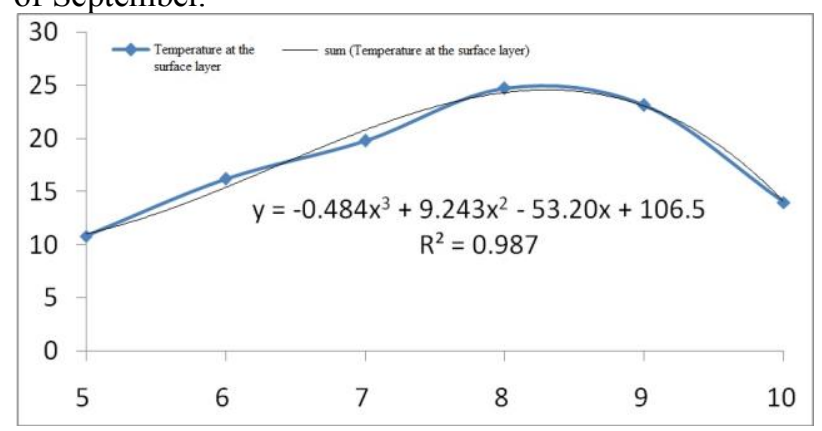

Fig.3 the change of low value of water temperature at the surface in Jiaozhou Bay in 1980

\section{Discussion}

\subsection{Time variation of water temperature}

From May to October, the water temperature varies within $10.80 \sim 26.53{ }^{\circ} \mathrm{C}$ in the waters of Jiaozhou Bay. The water temperature reaches above $10.00{ }^{\circ} \mathrm{C}$, but below $30.00{ }^{\circ} \mathrm{C}$. The high temperature curve in each month shows that the high water temperature reaches a maximum of $26.53{ }^{\circ} \mathrm{C}$ in August. The low temperature curve in each month shows that in August, the low water temperature reaches a maximum of $24.69{ }^{\circ} \mathrm{C}$. In the waters, the high and low water temperature both reach its highest in August.

\subsection{Regional changes of high water temperature}

In May, June, July, and August, the high water temperature is an upward trend in Jiaozhou Bay. The stations with high water temperature values are $\mathrm{H} 41, \mathrm{H} 36$, H41, and H36. In May and July, high water temperatures appear in the western waters of the top of bay. In June and August, high water temperatures appears in the western waters inside of bay mouth.

In September and October, the high water temperature is a downward trend in Jiaozhou Bay. The stations with high water temperature values are $\mathrm{H} 34$ and H82. In September, the high water temperature appears in the eastern waters outside the bay mouth. In October, the high water temperature appears in the southern waters outside the bay mouth.

\subsection{Regional changes of low water temperature}

In May, June, July, and August, the water temperature is low in Jiaozhou Bay. The stations with low water temperature values are H34, H82, H34 and H34. In May, July and August, the low water temperature appears in the eastern waters outside of bay mouth. In June, low water temperature appears in the southern waters outside the bay mouth.

In September and October, the low water temperature is a downward trend in Jiaozhou Bay. The stations with low water temperature values are at H41. In September and October, low water temperature appears in the western waters of the top of bay.

\subsection{The rate changes of water temperature}

The highest rate at which the high water temperature rises appears in June, and the highest rate at which the high water temperature drops appears in October. No matter rising rate or declining rate of high water temperature, the rate sequence from high to low is the rate of June $>$ the rate of October $>$ the rate of July $>$ the rate of September $>$ the rate of August. This shows that in June, the rising rate of high water temperature is the greatest. In October, the decling rate of high water temperature is relatively large.

The highest rate at which the low water temperature rises appears in June, and the highest rate at which the low water temperature drops appears in October. No matter rising rate or declining rate of low water temperature, the rate sequence from high to low is the rate of October $>$ the rate of June $>$ the rate of August $>$ the rate of July $>$ the rate of September. This shows that in June, the rising rate of low water temperature is the greatest. In October, the declining rate of low water temperature is relatively high.

Therefore, in June, the rising rate of high water temperature is the greatest, and the rising rate of low water temperature is relatively high. In October, the declining rate of high water temperature is relatively high, and the declining rate of low water temperature is the highest. 


\subsection{Monthly changes of water temperature}

The rise in water temperature is mainly caused by the short-wave radiation from the sun and the sky and the long-wave radiation from the atmosphere, which provides constant heat to the seawater, and is provided every season and every moment.

In the waters of Jiaozhou Bay, the high water temperature appears in the western waters of the top of bay in May. This reveals that the water temperature begin to rise first in the western waters of the top of Jiaozhou Bay.

In the waters of Jiaozhou Bay, in June, the rising rate of high water temperature is the fastest, and the rising rate of low water temperature is faster. Moreover, in June, the high water temperature appears inside of bay mouth, and the low water temperature appears in the southern waters outside of the bay. This reveals that the rising rate of high water temperature and low water temperature are both very fast in the waters inside of bay mouth and outside of bay.

The high water temperature in Jiaozhou Bay appears in the eastern waters outside of bay mouth in September. This reveals that the water temperature begin to decline first in the eastern waters outside of bay mouth.

The declining rate of high water temperature in Jiaozhou Bay is relatively fast in October, and the declining rate of low water temperature is the fastest at this time. Moreover, in October, the high water temperature appears in the southern waters outside the bay mouth, and the low water temperature appears in the western waters of the top of bay. This reveals that in the southern waters outside of the bay mouth and the western waters of the top of bay, the declining rate of the high water temperature and low water temperature are both very high.

\section{Conclusion}

From May to October, the water temperature varies in $10.80 \sim 26.53{ }^{\circ} \mathrm{C}$ in the waters of Jiaozhou Bay, and the length of the seawater temperature change is $15.73{ }^{\circ} \mathrm{C}$. The water temperature has reached above $10.00{ }^{\circ} \mathrm{C}$, but below $30.00{ }^{\circ} \mathrm{C}$. The high temperature curve of water temperature in each month shows that the high water temperature reaches a maximum of $26.53{ }^{\circ} \mathrm{C}$ in August. The low temperature curve of water temperature in each month shows that in August, the low water temperature reaches a maximum of $24.69{ }^{\circ} \mathrm{C}$ in August. In the Jiaozhou Bay water body, the high or low water temperature reaches its highest in August.

In May, June, July, and August, the high water temperature is increasing in Jiaozhou Bay. In May and July, high water temperatures appear in the western waters of the top of bay. In June and August, high water temperatures appear in the western waters inside of bay mouth. In September and October, the high water temperature in the Jiaozhou Bay water body is decreasing. In September, the high water temperature appears in the eastern waters outside of bay mouth. In October, the high water temperature appears in the southern waters outside of bay mouth.

In May, June, July, and August, the low water temperature is rising in Jiaozhou Bay. In May, July and August, low water temperatures appear in the eastern waters outside of the bay mouth. In June, low water temperatures appears in the southern waters outside of the bay mouth. In September and October, the low water temperature is a decreasing trend in Jiaozhou Bay. In September and October, low water temperatures appear in the western waters of the top of bay.

In June, the rising rate of high water temperature is the greatest, and the rising rate of low water temperature is relatively higher. In October, the declining rate of high water temperature is relatively high while the declining rate of low water temperature is the greatest.

\section{Acknowledgement}

This research was sponsored by Research Projects of Guizhou Nationalities University ([2014]02), Research Projects of Guizhou Province Ministry of Education (KY [2014] 266), Research Projects of Guizhou Province Ministry of Science and Technology (LH [2014] 7376). Thanks Prof. Qiang Shi for ardent help and nice suggestion.

\section{References}

1. Teaching-Research Office in Marine Thermology, Shandong Institute of Oceanology, Oceanology [M]. Qingdao: Shandong Institute of Oceanology Press, 1980,1-335.

2. Ming Yang, Dongxing Xia, Dongqi Gu, Zuo Xue, Aiping Feng. The evolution of geographical environment in coastal zone in Qingdao under the influence of global changes[J]. Advances in Marine Science, 2005, 23(3): 289-296

3. Dongfang Yang, Zhenqing Miao. Gulf Ecology (Volume 1) [M]. Beijing: Maritime Press, 2010, 1-320.

4. Dongfang Yang, Zhenqing Miao. Gulf Ecology (Volume 2) [M]. Beijing: Maritime Press, 2010, $1-330$.

5. Dongfang Yang, Zhenhui Gao, Peiyan Sun, Sheng Zhao, Youchi Zhang. Silicon limitation on primary production and its destiny in Jiaozhou Bay, ChinaVI The ecological variation process of the phytoplankton [J]. Chin. J. Oceanol. Limnol. 2006, 24(2): 186-203.

6. Dongfang Yang, Zhenhui Gao, Yingbin Yang, Sun Peiyan, Wang Xingping. Silicon limitation on primary production and its destiny in Jiaozhou Bay, ChinaVII the Complementary mechanism of the earth ecosystem [J]. Chin. J. Oceanol. Limnol. 2006, 24(4): 401-412.

7. Dongfang Yang, Zhenhui Gao, Jie Qin, Suxia Huo, Zhongqiang Li. Nutrient silicate complementary mechanism in earth ecosystem. [J]. Advances in Marine Science, 2006,24(4): 407-412. 
8. Dongfang Yang, Zhenhui Gao, Yuan Ma, Peiyan Sun, Yingbin Yang. The impact of environment changes in Jiaozhou Bay on marine biological resources [J]. Marine Environmental Science, 2006, 25(4): 39-42.

9. Dongfang Yang, Jianping $\mathrm{Wu}$, Yanfeng $\mathrm{Qu}$, Jun $\mathrm{Hu}$, Yanrong Zhou. The complementary mechanism of air and water temperature in earth ecosystem [J]. Advances in Marine Science, 2007, 25(1): 117-122.

10. Dongfang Yang, Zhenhui Gao, Wenfeng Li, Zijiang Yu, Changjiang Huang. The influence of marine ecological changes on the climate and crop planting relationship research [J]. Journal of Modern Academic Research. 2007, 7: 104-109.

11. D F YANG, Y CHEN, Z H GAO, et al. Silicon Limitation on primary production and its destiny in Jiaozhou Bay, China IV transect offshore the coast with estuaries [J]. Chin. J. Oceanol. Limnol. 2005, 23(1): 72-90.

12. Dongfang Yang, Fan Wang, Zhenhui Gao, et al. The ecological phenomenon of floating algae in Jiaozhou Bay [J]. Marine Science, 2004, 28(6): 71-74.

13. State Oceanic Administration. The specification for marine monitoring. Beijing: Maritime Press, 1991 